\title{
ANTIHYPERGLYCEMIC ACTIVITY OF PHENYL AND ORTHO-HYDROXY PHENYL LINKED IMIDAZOLYL TRIAZOLO HYDROXAMIC ACID DERIVATIVES
}

\author{
DILIPKUMAR PAL ${ }^{2 *}$, SUSHIL KUMAR ${ }^{3}$, SUPRIYO SAHA ${ }^{1}$ \\ 1Department of Pharmaceutical Sciences, Sardar Bhagwan Singh Post Graduate Institute of Biomedical Sciences and Research. Balawala, \\ Dehradun 248001, Uttarakhand, India, 'Department of Pharmaceutical Sciences, Guru Ghasidas Vishwavidyalaya (A Central University), \\ Koni, Bilaspur, Chhattisgarh 495009, India, ${ }^{3}$ Faculty of Pharmacy, IFTM University, Moradabad, (U. P.), India \\ Email: drdilip2003@yahoo.co.in
}

Received: 18 Aug 2017 Revised and Accepted: 02 Nov 2017

\section{ABSTRACT}

Objective: The paradigm was to establish phenyl and ortho-hydroxy phenyl-linked imidazolyl triazolo hydroxamic acid derivatives as an antihyperglycemic agent.

Methods: $100 \mathrm{mg} / \mathrm{Kg}$ body weight dose of phenyl and ortho-hydroxy Phenyl linked Imidazolyl triazolo Hydroxamic Acid derivatives (FP1-FP12) and standard glibenclamide were administered per os (p. o.) in the streptozotocin-induced hyperglycemic rats by glucose oxidase-peroxidase method and statistically evaluated by one-way analysis of variance.

Results: FP3 was potent as compare to standard glibenclamide $(\mathrm{P}<0.05-0.001)$ and FP6, FP9, and FP4 were also effective as an antihyperglycemic agent. The activity profile of the molecule was as follows FP9 $<$ FP10 $<$ FP $4<\mathrm{FP} 6<\mathrm{FP} 12<\mathrm{FP} 3$. This study reflects that presence of para methoxy phenyl group linked with phenyl group in surface recognition portion and imidazolyl triazole group in linker portion associated with a sulfamethyl hydroxamic acid group in metal identifying the part in case of FP3 was resemble for antihyperglycemic activity.

Conclusion: It was concluded that compounds possessing electron releasing groups on the aromatic rings in the surface recognition part considerably enhanced the antihyperglycemic activity.

Keywords: Hydroxamic Acid, Antihyperglycemic, Streptozotocin, Glibenclamide

(C) 2017 The Authors. Published by Innovare Academic Sciences Pvt Ltd. This is an open-access article under the CC BY license (http://creativecommons.org/licenses/by/4.0/) DOI: http://dx.doi.org/10.22159/ijpps.2017v9i12.22086

\section{INTRODUCTION}

HDACI (Histone Deacetylase Inhibitor) was associated with cell cycle arrest and create obstruction related to the transcriptional resolution of p21WAF1/CIP1 (cycling-subordinate kinase inhibitor 1 or CDKcooperating protein), p27KIP1 (a cell cycle administrative protein that connects with cycling-CDK2 and CDK4, repressing the cell cycle movement at G1 phase), GADD45 (development capture and DNA harm), restraint of cyclin A, cyclin D, and thymidylate synthetase [1-2]. Synthesized molecules (FP1-FP12) was possessed with imidazolyl-1,2,4triazole group amalgamated with a hydroxamic acid group in the terminal position and phenyl/ortho hydroxyl phenyl group in the receptor surface recognition portion, consideration of standard structure SAHA (Suberoyl Anilide Hydroxamic Acid) [3] (fig. 1). The previous study reflects that synthesized molecules (FP1-FP12) showed good HDAC inhibition and MCF-7 cell line inhibition[4], DPPH radical scavenging activity, anti-inflammatory and analgesic activity and brine shrimp lethality assay, antimicrobial and antifungal activity [5-6]. In this article, the anti-hyperglycemic activity of the synthesized molecules (FP1-FP12) was evaluated in streptozotocin-induced hyperglycemic rats. There was structural similarity of synthesized molecules (FP1-FP12) and glimepiride, glibenclamide as both structures contains- $\mathrm{NH}-\mathrm{C}=\mathrm{O}-\mathrm{NH}$-and imidazole group and 1,2, 4-triazole moiety in sitagliptin was similar with linker portion of FP1-FP12 due to containing the imidazolyl-triazole group. So, this data encourage us to perform an anti-hyperglycemic activity of the synthesized molecule.

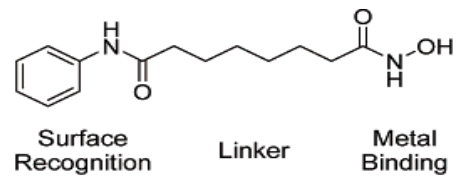

Fig. 1: Structure of basic pharmacophore of SAHA and synthesized HDAC inhibitor

\section{MATERIALS AND METHODS}

Chemicals

Streptozotocin was purchased from Sisco Research Laboratories Ltd, Andheri Mumbai, India. The standard drug glibenclamide was procured from Cadila Pharmaceuticals Limited, Ahmedabad, India.

\section{Synthesis}

The synthesis of hydroxamic acid derivatives (FP1-FP12) were previously done by fusion of 2-chloro-N-hydroxyacetamide with 2[(4-amino-3-phenyl/3-(2-hydroxyphenyl)-4H-1，2, 4-triazol-5-yl) sulfanyl]-N-hydroxyacetamide (by Reid-Hindel Process) and in final step in presence of pyridine and zeolite, 2-[[(3-substituted phenyl[4-\{(4-(substituted phenyl) ethylidine-2-Phenyl-1,3-Imidazol-5One\}] (-4H-1,2,4-triazol-5-yl) sulfanyl]-N-hydroxyacetamide was synthesized (fig. 2). All characterizations of the chemical structure were done by ${ }^{1} \mathrm{H}$ NMR, FTIR and Mass spectrometric data [4].

\section{Animals}

Wistar albino rats of either gender weighing 130-170 g were obtained from Sri Guru Ram Rai Institute of Technology and Science (SGRRITS), Patel Nagar, Dehradun [264/PO/ReBi/ S/02/CPCSEA]. The animals were divided into several groups of six animals each. All the animals were kept under a standard ambient environment of temperature $\left(22 \pm 3{ }^{\circ} \mathrm{C}\right)$ and relative humidity of $50 \pm 5 \%$. Although the relative humidity should be at least $30 \%$ and preferably not exceed $70 \%$ other than during room cleaning the aim should be 50-60\%. Artificial lights were used with $12 \mathrm{~h}$ light and $12 \mathrm{~h}$ dark sequence. Animals may be group-caged by dose, but the number of animals per cage must not interfere with clear observations of each animal. Institutional Animal Ethical Committee (IAEC) as constituted by CPSCEA has given approval for all experimental procedures and protocols used in this study (IAEC, Reg. No.273/CPCSEA). 


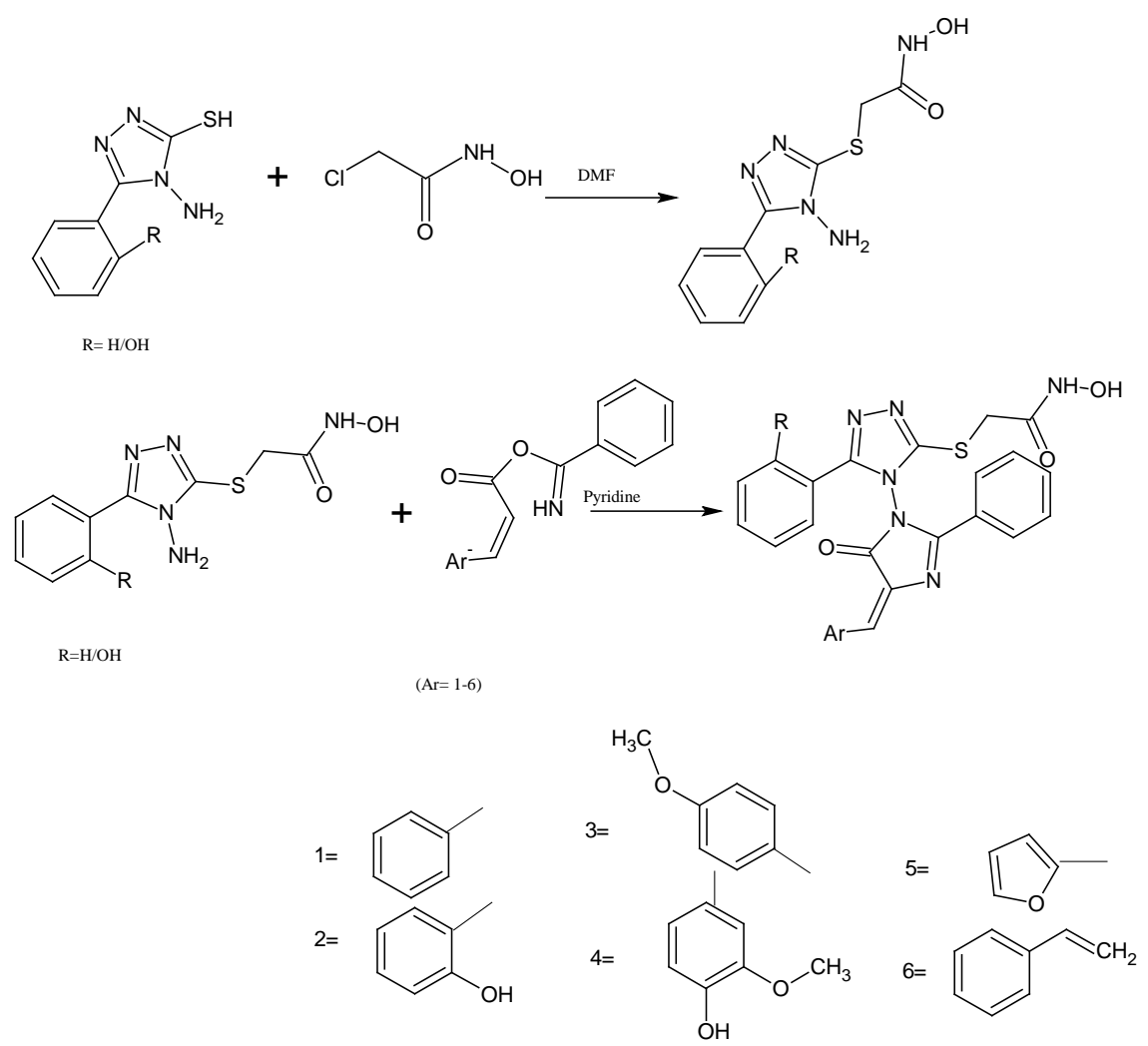

Fig. 2: General procedure to synthesize FP1-FP12

\section{Preparation of test compounds}

Synthesized molecules (FP1-FP12) and standard drug glibenclamide were prepared as a suspension in $1 \% \mathrm{v} / \mathrm{v}$ tween 80 . Control group was administrated with $0.1 \mathrm{ml}$ of tween 80 suspensions orally.

\section{Acute toxicity study}

The acute toxicity study was carried out as per OECD guidelines to calculate the successful dose of the test compounds. Wistar albino rats of either sex weighing between $130-170$ g were divided into several groups with 6 animals in each group. Animals were starved for $12 \mathrm{~h}$ before the experiment. Those test animals died during the test should be contingent to necropsy. On the day of the experiment, animals were treated with sample molecules to different groups in an increasing order of $10,50,100,250,500$ and $1000 \mathrm{mg} / \mathrm{kg}$ body weight by oral feeding. As per this oral toxicity experiment, it was detected that in the highest dose of $1000 \mathrm{mg} / \mathrm{kg}$ body weight, all test animals were found to be safe. So, $1 / 10^{\text {th }}$ of the highest tolerated dose, $100 \mathrm{mg} / \mathrm{kg}$ body weight was chosen for antihyperglycemic activity [7].

\section{Experimental design}

Antihyperglycemic activity of synthetic hydroxamic acid derivatives (FP1-FP12) was assessed in normal and streptozotocin-induced hyperglycemic rats. In during the experiment, animals fasted for overnight long $16 \mathrm{~h}$ period with the free environment of water intake [8].

\section{Induction of experimental hyperglycemia}

Streptozotocin (STZ) was dissolved in cold citrate buffer (pH 4.5) and nicotinamide was dissolved in normal physiological saline solution $(0.9 \% \mathrm{w} / \mathrm{v}$ sodium chloride solution). Hyperglycemia was induced by $65 \mathrm{mg} / \mathrm{kg}$ intraperitoneal injection in overnight fasted rats, then after $15 \mathrm{~min}$ intraperitoneal administration of $110 \mathrm{mg} / \mathrm{kg}$ of nicotinamide. An elevated plasma glucose level indicates hyperglycemia after seven days of induction. Animals with blood glucose concentrations more than $200 \mathrm{mg} / \mathrm{dL}$ were used for the study [9].
Acute hypoglycemic effect of synthesized hydroxamic acid derivatives (FP1-FP12) on normoglycemic rats

Acute hypoglycemia study was performed in overnight fasted normal rats. Normal rats were divided into fourteen groups, each consisting of six rats. Group, 1 was controlling animals administered with an equal volume of water. Group 2 to group 13 was treated orally with the suspension of (FP1-FP12) at a dose of $100 \mathrm{mg} / \mathrm{kg}$, per os and group 14 (positive control) was treated with standard glibenclamide $(600 \mu \mathrm{g} / \mathrm{kg})$ [10]. A blood sample was withdrawn from the retro-orbital plexus at $0 \mathrm{~h}, 2 \mathrm{~h}, 4 \mathrm{~h}, 6 \mathrm{~h}, 8 \mathrm{~h}, 24 \mathrm{~h}$ of glucose administration and blood glucose levels were estimated within $1 \mathrm{~h}$, by glucose oxidase-peroxidase method [11].

\section{Effect of synthesized hydroxamic acid derivatives (FP1-FP12)} on streptozotocin-induced hyperglycemic rats

The rats were divided into fifteen groups of six rats in each group: Group 1: Normal rats treated with vehicle alone (1\% tween $80,1 \mathrm{ml}$ per orally); Group 2: Hyperglycemic rats treated with vehicle alone (1\% tween 80, $1 \mathrm{ml}$ per orally); Group 3: Hyperglycemic rats treated with FP1 at the dose $100 \mathrm{mg} / \mathrm{kg}$. Group 4: Hyperglycemic rats treated with FP2 at the dose $100 \mathrm{mg} / \mathrm{kg}$. Group 5: Hyperglycemic rats treated with FP3 at the dose $100 \mathrm{mg} / \mathrm{kg}$. Group 6: Hyperglycemic rats treated with FP4 at the dose $100 \mathrm{mg} / \mathrm{kg}$. Group 7: Hyperglycemic rats treated with FP5 at the dose $100 \mathrm{mg} / \mathrm{kg}$. Group 8: Hyperglycemic rats treated with FP6 at the dose 100 $\mathrm{mg} / \mathrm{kg}$. Group 9: Hyperglycemic rats treated with FP7 at the dose $100 \mathrm{mg} / \mathrm{kg}$. Group 10: Hyperglycemic rats treated with FP8 at the dose $100 \mathrm{mg} / \mathrm{kg}$. Group 11: Hyperglycemic rats treated with FP9 at the dose $100 \mathrm{mg} / \mathrm{kg}$. Group 12: Hyperglycemic rats treated with FP10 at the dose $100 \mathrm{mg} / \mathrm{kg}$. Group 13: Hyperglycemic rats treated with FP11 at the dose $100 \mathrm{mg} / \mathrm{kg}$. Group 14: Hyperglycemic rats treated with FP12 at the dose $100 \mathrm{mg} / \mathrm{kg}$. Group 15: Hyperglycemic rats treated with Glibenclamide at the dose of $600 \mu \mathrm{g} / \mathrm{kg} .0 .1 \mathrm{ml}$ of halothane anaesthetic agent was administered in the shaved portion of the abdomen. A blood sample was withdrawn from the retroorbital plexus at $0 \mathrm{~h}, 2 \mathrm{~h}, 4 \mathrm{~h}, 6 \mathrm{~h}, 8 \mathrm{~h}, 24 \mathrm{~h}$ of glucose administration and blood glucose levels were estimated within $1 \mathrm{~h}$, by glucose oxidase-peroxidase method [12-13]. 


\section{Statistical analysis}

The result of antihyperglycemic activity was expressed as mean \pm SEM and was statistically validated using one-way analysis of variance (ANOVA) followed by Dunnett'st-test. The probability value with 0.05 or less was considered statistically significant. Statistical analysis was performed by Graph Pad Prism software version 5.01, Graph Pad Software Inc. USA.

\section{RESULTS}

\section{Acute oral toxicity study}

In acute toxicity study, synthesized molecules (FP1-FP12) treated animals did not show any change in their behavioural pattern. There was no significant difference in the body weights and food intake as compared to the vehicle-treated group. The test animals were observed continuously for $3 \mathrm{~h}$ for any behavioural and autonomic profiles, after that check for every 30 min for next $4 \mathrm{~h}$ and finally for next $24 \mathrm{~h}$ or till death. As per this oral toxicity experiment, it was detected that in the highest dose of $1000 \mathrm{mg} / \mathrm{kg}$ body weight, all test animals were found to be safe [14].
Acute hypoglycemic effect of synthesized hydroxamic acid derivatives (FP1-FP12) on normoglycemic rats

The effect of synthesized molecules (FP1-FP12) on normal fasted rats was shown in (fig. 3). In normoglycemic rats, all synthesized molecules (FP1-FP12) were statistically significant with the $P$ value less than 0.001 from control except FP1. Among the samples, FP9 showed better effect as $72.57 \mathrm{mg} / \mathrm{dL}, 72.14 \mathrm{mg} / \mathrm{dL}, 71.91 \mathrm{mg} / \mathrm{dL}, 71.82 \mathrm{mg} / \mathrm{dL}, 71.78$ $\mathrm{mg} / \mathrm{dL}, 71.99 \mathrm{mg} / \mathrm{dL}$ after $0 \mathrm{~h}, 2 \mathrm{~h}, 4 \mathrm{~h}, 6 \mathrm{~h}, 8$ h, 24 h respectively; FP10 showed slightly less effective than FP9 as $73.73 \mathrm{mg} / \mathrm{dl}, 73.59 \mathrm{mg} / \mathrm{dL}$, $73.41 \mathrm{mg} / \mathrm{dL}, 72.37 \mathrm{mg} / \mathrm{dL}, 72.28 \mathrm{mg} / \mathrm{dL}, 72.36 \mathrm{mg} / \mathrm{dL}$ after $0 \mathrm{~h}, 2 \mathrm{~h}, 4$ h, 6 h, 8 h, 24 h respectively; FP4 showed slightly less effective than FP10 as $73.81 \mathrm{mg} / \mathrm{dL}, 73.49 \mathrm{mg} / \mathrm{dL}, 73.11 \mathrm{mg} / \mathrm{dL}, 72.87 \mathrm{mg} / \mathrm{dL}, 72.37$ $\mathrm{mg} / \mathrm{dL}, 72.98 \mathrm{mg} / \mathrm{dL}$ after $0 \mathrm{~h}, 2 \mathrm{~h}, 4 \mathrm{~h}, 6 \mathrm{~h}, 8 \mathrm{~h}, 24 \mathrm{~h}$ respectively whereas standard Glibenclamide showed $76.27 \mathrm{mg} / \mathrm{dL}, 72.87 \mathrm{mg} / \mathrm{dL}$, $69.24 \mathrm{mg} / \mathrm{dL}, 66.57 \mathrm{mg} / \mathrm{dL}, 63.21 \mathrm{mg} / \mathrm{dL}, 60.05 \mathrm{mg} / \mathrm{dL}$ after $0 \mathrm{~h}, 2 \mathrm{~h}, 4$ h, 6 h, 8 h, 24 h. The activity diagram of acute hypoglycemic effect in the case of normoglycemic rats was $\mathrm{FP} 1<\mathrm{FP} 5<\mathrm{FP} 2<\mathrm{FP} 7<\mathrm{FP} 11$. However, the rats treated with synthesized molecules (FP1-FP12) and glibenclamide were showed a marked reduction in blood glucose levels [15-16].

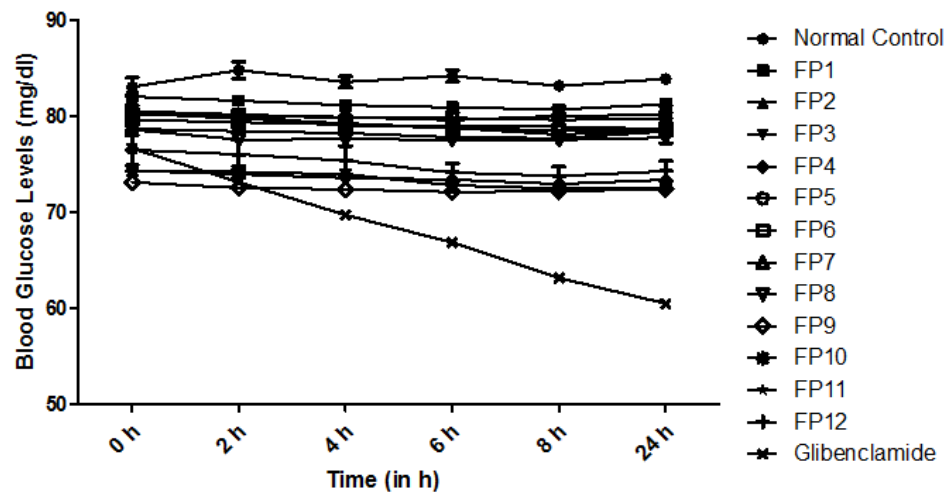

Fig. 3: Acute hypoglycemic effect of synthesized hydroxamic acid derivatives (FP1-FP12) on normoglycemic rats (n=6). mean \pm SD

Effect of synthesized hydroxamic acid derivatives (FP1-FP12) on streptozotocin-induced hyperglycemic rats

Administration of FP1-FP12 on Streptozotocin-induced hyperglycemic rats showed a marked reduction in serum glucose level after $2 \mathrm{~h}, 4 \mathrm{~h}, 6$, $8 \mathrm{~h}$ and $24 \mathrm{~h}$ interval and all data was shown in (table 1). In streptozotocin-induced rats, FP6 and FP9 were statistically significant with the $\mathrm{P}$ value less than 0.05 from control. Among the samples, FP9 showed better effect as $424.8 \mathrm{mg} / \mathrm{dL}, 386.7 \mathrm{mg} / \mathrm{dL}, 297.2 \mathrm{mg} / \mathrm{dL}$, $246.7 \mathrm{mg} / \mathrm{dL}, 198 \mathrm{mg} / \mathrm{dl}, 152.2 \mathrm{mg} / \mathrm{dl}$ after 0 h, 2 h, 4 h, 6 h, 8 h, $24 \mathrm{~h}$ respectively; FP6 showed slightly less effective than FP9 as 326.6 $\mathrm{mg} / \mathrm{dl}, 308.7 \mathrm{mg} / \mathrm{dl}, 289.7 \mathrm{mg} / \mathrm{mg} / \mathrm{dl}, 273.8 \mathrm{mg} / \mathrm{dl}, 257.3 \mathrm{mg} / \mathrm{dl}, 234.8$ $\mathrm{mg} / \mathrm{dl}$ after $0 \mathrm{~h}, 2 \mathrm{~h}, 4 \mathrm{~h}, 6 \mathrm{~h}, 8 \mathrm{~h}, 24 \mathrm{~h}$ respectively; FP4 showed slightly less effective than FP6 as $355.8 \mathrm{mg} / \mathrm{dl}, 316.7 \mathrm{mg} / \mathrm{dl}, 227.3 \mathrm{mg} / \mathrm{dl}$, $182.3 \mathrm{mg} / \mathrm{dl}, 178.4 \mathrm{mg} / \mathrm{dl}, 145.5 \mathrm{mg} / \mathrm{dl}$ after $0 \mathrm{~h}, 2 \mathrm{~h}, 4 \mathrm{~h}, 6 \mathrm{~h}, 8 \mathrm{~h}, 24 \mathrm{~h}$ respectively whereas standard glibenclamide showed $210.5 \mathrm{mg} / \mathrm{dl}$, $179.8 \mathrm{mg} / \mathrm{dl}, 189.3 \mathrm{mg} / \mathrm{dl}, 221.3 \mathrm{mg} / \mathrm{dl}, 178.8 \mathrm{mg} / \mathrm{dl}, 158.6 \mathrm{mg} / \mathrm{dl}$ after $0 \mathrm{~h}, 2 \mathrm{~h}, 4 \mathrm{~h}, 6 \mathrm{~h}, 8 \mathrm{~h}, 24 \mathrm{~h}$. The activity diagram of the effect of synthesized molecules on streptozotocin-induced rats was FP9 $<$ FP10 $<$ FP4 $<$ FP $6<$ FP12 $<$ FP3. The antihyperglycemic activity of most of the molecules was active mostly at $4 \mathrm{~h}$ interval. However, the rats treated with synthesized molecules (FP1-FP12) and Glibenclamide were showed a marked reduction in blood glucose levels in case of streptozotocin-induced hyperglycemic rats [17-19].

Table 1: Effect of synthesized hydroxamic acid derivatives (FP1-FP12) on streptozotocin induced hyperglycemic rats (n=6)

\begin{tabular}{|c|c|c|c|c|c|c|}
\hline \multirow[t]{2}{*}{ Treatment } & \multicolumn{6}{|c|}{ Mean blood glucose concentration (mg/dl) \pm SEM } \\
\hline & $\mathbf{0 ~ h}$ & $2 \mathrm{~h}$ & $4 \mathrm{~h}$ & $6 \mathrm{~h}$ & $8 \mathrm{~h}$ & $24 \mathrm{~h}$ \\
\hline Normal Control & $205.2 \pm 1.34$ & $198.4 \pm 1.78$ & $188.8 \pm 1.69$ & $178.8 \pm 0.89$ & $161.2 \pm 2.82$ & $154.3 \pm 2.25$ \\
\hline FP1 & $224.5 \pm 1.32$ & $246.2 \pm 1.49$ & $227.7 \pm 1.25$ & $194.6 \pm 1.89$ & $172.1 \pm 1.39$ & $179.7 \pm 1.89$ \\
\hline FP2 & $264.7 \pm 1.77$ & $248.2 \pm 1.35$ & $217.4 \pm 1.46$ & $184.8 \pm 1.63$ & $178.4 \pm 1.82$ & $168.4 \pm 1.37$ \\
\hline FP3 & $296.7 \pm 1.38$ & $278.8 \pm 1.29$ & $275.2 \pm 1.57$ & $224.2 \pm 1.53$ & $198.3 \pm 1.27$ & $174.5 \pm 1.62$ \\
\hline FP4 & $355.8 \pm 1.84$ & $316.7 \pm 1.28$ & $227.3 \pm 1.25$ & $182.3 \pm 1.45$ & $178.4 \pm 1.27$ & $145.5 \pm 1.21$ \\
\hline FP5 & $238.5 \pm 1.28$ & $228.6 \pm 1.27$ & $217.2 \pm 1.16$ & $202.3 \pm 1.21$ & $194.4 \pm 1.54$ & $182.6 \pm 1.12$ \\
\hline $\mathrm{FP}^{*}$ & $326.6 \pm 1.28$ & $308.7 \pm 1.78$ & $289.7 \pm 1.42$ & $273.8 \pm 0.79$ & $257.3 \pm 1.52$ & $234.8 \pm 1.48$ \\
\hline FP7 & $238.2 \pm 1.12$ & $226.4 \pm 1.11$ & $212.8 \pm 1.13$ & $202.2 \pm 0.66$ & $189.2 \pm 1.45$ & $165.1 \pm 1.10$ \\
\hline FP8 & $278.2 \pm 1.12$ & $252.5 \pm 1.42$ & $223.4 \pm 1.03$ & $196.2 \pm 1.21$ & $163.5 \pm 1.23$ & $153.7 \pm 0.83$ \\
\hline FP9* $^{*}$ & $424.8 \pm 1.88$ & $386.7 \pm 1.92$ & $297.2 \pm 1.32$ & $246.7 \pm 1.15$ & $198.5 \pm 1.49$ & $152.2 \pm 0.98$ \\
\hline FP10 & $372.8 \pm 1.12$ & $346.1 \pm 1.42$ & $207.1 \pm 1.14$ & $184.2 \pm 1.24$ & $167.3 \pm 1.07$ & $149.2 \pm 1.94$ \\
\hline FP11 & $249.2 \pm 1.28$ & $238.1 \pm 1.42$ & $212.4 \pm 1.58$ & $197.1 \pm 0.82$ & $192.5 \pm 1.43$ & $188.7 \pm 1.42$ \\
\hline FP12 & $324.8 \pm 1.27$ & $297.8 \pm 1.62$ & $272.8 \pm 1.62$ & $244.6 \pm 1.04$ & $192.4 \pm 1.30$ & $153.8 \pm 1.21$ \\
\hline Glibenclamide & $210.5 \pm 1.75$ & $179.8 \pm 1.19$ & $189.3 \pm 1.82$ & $221.3 \pm 1.67$ & $178.8 \pm 1.17$ & $158.6 \pm 1.54$ \\
\hline
\end{tabular}

Note: ${ }^{*} P<0.05$ significant from control. mean \pm SD. 


\section{DISCUSSION}

Management of hyperglycemia without side effect is still a challenge for pharmaceutical development. This has led to an increasing demand for the synthetic molecule with antihyperglycemic activity and fewer side effects. Hyperglycemic subjects display more changes in dynamics of insulin secretion, such as blunting of the first phase insulin secretion and disruption of the insulin secretory pulses. STZ [2-deoxy-2-(3-methyl-3-nitrosoureido)-D-glucopyranose] is an antibiotic that is used to induce experimental hyperglycemia in animals [20-22]. STZ-induced hyperglycemia may be due to vitiate glucose oxidation and reduction of insulin biosynthesis and secretion. The toxicity of STZ is due to DNA alkylation of its methyl nitrosourea moiety, mainly 0 at 6 position of guanine. The transfer of methyl group from STZ to the DNA molecule causes damage which results in fragmentation of DNA and functional defects of the beta cells. Moreover, STZ has potential to act as an intracellular nitric oxide (NO) donor and generates reactive oxygen species (ROS). The synergistic action of both NO and ROS may also contribute to DNA fragmentation and other deleterious changes caused by STZ [23-24]. Hydroxamic acid derivatives are versatile with pharmacological activity as anti-HDAC, anti-cancer against various cell line as MCF_7, HeLa carcinoma, anti-inflammatory, analgesic, so it may act as antihyperglycemic agent. In normoglycemic rats, FP9, FP10, FP4 are effective as compare to standard Glibenclamide. $\mathrm{r}^{2}$ and $\mathrm{F}$ value in acute hypoglycemic activity on normoglycemic rats are $0.8938,42$ and $P$ value less than 0.001 . In the case of streptozotocin-induced hyperglycemic rats, FP9, FP6, FP4 showed good antihyperglycemic activity as standard glibenclamide. $\mathrm{r}^{2}$ and $\mathrm{F}$ value in acute hypoglycemic activity on normoglycemic rats are $0.2536,1.856$ and the P value less than 0.05 [25-26]. STZ-induced hyperglycemia was characterized by a severe loss of body weight [27]. The decrease in body weight in hyperglycemic rats showed that the loss or degradation of structural proteins. Structural proteins are contributed to body weight. When hyperglycemic rats were treated with synthesized hydroxamic acid derivatives (FP1-FP12), the weight loss was reversed. The capability of FP1-FP12 is to protect the body from weight loss as a result of to reduce hyperglycemia. The outcomes of this study showed that synthesized hydroxamic acid derivatives (FP1-FP12) have a hypoglycemic effect in streptozotocin-induced diabetic rats [28-38]. The antihyperglycemic effects of FP1-FP12 may be mediated through an increase in insulin secretion, the inhibition of gluconeogenesis and glycogenolysis and/or protection of pancreatic $\beta$-cells from streptozotocin and glucose-induced oxidative stress.

\section{CONCLUSION}

It was concluded that the compounds possessing electron releasing groups on the aromatic rings in the surface recognition part considerably enhanced the antihyperglycemic activity. This study refers that hydroxamic acid derivatives not only target chromatin remodeling associated with cancer but also effective against diabetes mellitus.

\section{AUTHORS CONTRIBUTION}

D. P: Guidance, data interpretation and compilation as mentor. S. S: Performing antihyperglycemic activity as per protocol and guidance. $\mathrm{S}$ K: Guide during the practical work as a co mentor.

\section{ACKNOWLEDGEMENT}

One of the authors shares his gratitude towards H. O. D. SBSPGI and H. O. D. SGRRITS for providing facilities to carry out some research works.

\section{CONFLICTS OF INTERESTS}

The authors declare no conflict of interest

\section{REFERENCES}

1. Pal DK, Saha S. Hydroxamic acid-a novel molecule for anticancer therapy. J Adv Pharm Tech Res 2012;3:92-9.

2. Wang CY, Lee LH. Mutagenicity and antibacterial activity of hydroxamic acids. Am Soc Microbiol 1977;11:753-5.
3. Pal D, Banerjee S, Ghosh A. Dietary induced cancer prevention: an expanding research arena of emerging diet, related to health care system. J Adv Pharm Tech Res 2012;3:16-24.

4. Saha S, Pal DK, Kumar S. Design, synthesis and antiproliferative activity of hydroxyacetamide derivatives against HeLa cervical carcinoma cell and breast cancer cell line. Trop J Pharm Res 2016;15:1319-26.

5. Saha S, Pal DK, Kumar S. Antifungal and antibacterial activities of phenyl and ortho-hydroxy phenyl linked imidazolyl triazolo hydroxamic acid derivatives. Inventi Rapid Med Chem 2017;2:42-9.

6. Saha S, Pal DK, Kumar S. Cytotoxicity study by BSL Assay, genotoxicity study by alium cepa assay, antioxidative and metal chelating studies of the hydroxyacetamide derivatives. Ind J Exp Biol 2017. [Article in Press]

7. OCED/OCDC and OECD, Guidelines for testing of chemicals. revised draft guidelines 423 , acute oral toxicity class method, Revised document; 2000.

8. Karan SK, Mishra SK, Pal DK, Mondal A. Isolation of $\beta$-sitosterol and evaluation of antidiabetic activity of Aristo lochiaindica in alloxan-induced diabetic mice with a reference to in vitro antioxidant activity. J Med Plant Res 2012;6:1219-23.

9. Akah PA, Uzodinma SU, Okolo CE. Antidiabetic activity of aqueous and methanol extract and fractions of Gongronema latifolium (Asclepidaceae) leaves in alloxan diabetic Rats. J Appl Pharm Sci 2011;1:99-102.

10. Pattan SR, Suresh C, Pujar VD, Reddy VVK, Rasal VP, Koti BC. Synthesis and antidiabetic activity of amino-[5' $(4-$ sulphonylbenzylidene)-2,4-thiazolidinedione]-7-chloro-6flurobenzothiazole. Ind J Exp Biol 2005;44B:2404-8.

11. Kumar R, Arora V, Ram V, Bhandari A, Vyas P. Hypoglycemic and hypolipidemic effect of allopolyherbal formulations in streptozotocin induced diabetes mellitus in rats. Int J Diabetes Mellitus 2015;2:45-50.

12. Emayavaramban M, Santhi N, Gopi C, Manivannan C, Raguraman A. Synthesis, characterization and anti-diabetic activity of 1,3,5-triaryl-2-pyrazolines in acetic acid solution under ultrasound irradiation. Int Let Chem Phys Astr On 2013;14:172-85.

13. Jadhav R, Puchchakayala G. Hypoglycemic and antidiabetic activity of flavonoids: boswellic acid, ellagic Acid, quercetin, rutin on streptozotocin-nicotinamide induced type 2 diabetic rats. Int J Pharm Pharm Sci 2012;4:251-6.

14. Pal D, Tripathi R, Pandey DD, Mishra P. Synthesis, characterization and evaluation of substituted oxadiazole and thiadiazole derivatives. J Adv Pharm Tech Res 2014;5:196-201.

15. Ahmed SM, Swamy BMV, Gopkumar P, Dhanapal R, Chandrashekara VM. Anti-diabetic activity of Terminalia Catappa Linn. leaf extracts in alloxan-induced diabetic rats. Iran J Pharmacol Ther 2005;4:36-9.

16. Gandhi GR, Sasikumar P. Antidiabetic effect of Merremiae marginata Burm. F. in streptozotocin induced diabetic rats. Asia Pac J Trop Biomed 2012;2:281-6.

17. Prisilla DH, Balamurugan R, Shah HR. Antidiabetic activity of methanol extract of Acorus calamus in STZ induced diabetic rats. Asia Pac J Trop Biomed 2012;2:S941-6.

18. Nasry MR, Abo-Youssef AM, Abd El-Latif HA. Anti-diabetic activity of the petroleum ether extract of guar gum in streptozotocin-induced diabetic rats: a comparative study. Beni-Suef Uni J Bas Appl Sci 2013;2:51-9.

19. Shankar PK, Kumar V, Rao N. Evaluation of antidiabetic activity of Ginkgo Biloba in streptozotocin induced diabetic rats. Iran J Pharmacol Ther 2005;4:16-9.

20. Jaiswal J, Bhardwaj H, Srivastava S, Gautam H, Sharma S, Rao CV. Anti-diabetic activity of methanolic extract of Calotropis Gigantea seeds on STZ induced diabetic rats. Int J Pharm Pharm Sci 2013;6:254-7.

21. Verma N, Shakya VK, Saxena RC. Antidiabetic activity of glycoside isolated from Gymnema sylvestre in streptozotocin induced diabetic rats. Asia J Chem 2008;20:5033-6.

22. Suthar M, Rathore GS, Pareek A. Antioxidant and antidiabetic activity of Helicteres isora (L.) fruits. Indian J Pharm Sci 2009;71:695-9. 
23. Kumar S, Malhotra R, Kumar D. Antidiabetic and free radicals scavenging potential of Euphorbia hirta flower extract. Indian J Pharm Sci 2010;72:533-7.

24. Devaki K, Sangeetha M, Hemmalakshmi S, Priyanga S. In vivo antidiabetic potential of Cyclea Peltata in streptozotocin induced diabetic rats. Asian J Pharma Clin Res 2015;8:103-8.

25. Sailaja R, Krishna MG, Prathima S. Evaluation of anti-diabetic activity of Hydnocarpus laurifolia in streptozotocin induced diabetic rats. Asian J Pharma Clin Res 2014;7:62-4.

26. Khatri SK, Mahalaxmi R, Nikhila R. Formulation and evaluation of wound healing activity of linezolid topical preparations on diabetic rats. Int J Appl Pharma 2016;8:30-6.

27. Saiful I, Moyenuddin PK. Antihyperglycemic activity of edible mushroom Lentinus edodes in alloxan induced diabetic swiss albino mice. Int J Pharma Clin Res 2014;6:121-6.

28. Satyavani K, Gurudeeban S. Insight on solid lipid nanoparticles: characterization and application in diabetes mellitus. J Critical Rev 2016;3:11-6.

29. Pal D, Nayak A. Novel tamarind seed polysaccharide-alginate mucoadhesive microspheres for oral gliclazide delivery: in vitro-in vivo evaluation. Drug Delivery 2012;19:125-31.

30. Karan S, Mishra S, Pal D. Isolation of beta sitosterol and evaluation of antidiabetic activity of Aristolochia indica in alloxan induced diabetic mice with a special reference to in vitro antioxidant activity. J Med Plant Res 2012;6:1219-23.

31. Pal D, Maity P, Samanta K. Antioxidant activity of aerial parts of H. Difformis. Asian J Chem 2009;22:2459-61.

32. Pal D, Maity P, Samanta K. The in vitro antioxidant activity of leaves of F. rumphii Blume. Asian J Chem 2010;22:8246-8.

33. Venkidesh R, Mandal SC, Pal D, Mohanta LS, Sarvanakumar A. Antidiabetic activity of Smilax chinensis L. extract in alloxan induced rats. Int J Pharma Pharm Sci 2010;2:51-4.

34. Karan SK, Mondal A, Mishra SK, Pal D, Rout KK. Antidiabetic effect of Streblus asper in streptozotocin-induced diabetic rats. Pharm Biol 2013;51:369-75.

35. Mondal A, Maity T, Pal D. Hypoglycaemic effect of Melothria heterophylla in streptozotocin induced diabetic rats. Pharm Biol 2012;50:1151-6.

36. Nayak A, Pal D. Ionotropically-gelled mucoadhesive beads for oral metformin $\mathrm{HCl}$ delivery: formulation, optimization and antidiabetic evaluation. J Sci Ind Res 2012;72:851-8.

37. Pal D, De T, Baral A. DPP-4 inhibitor linagliptin: a new antidiabetic drug in the treatment of type-II diabetes. Int J Pharm Pharm Sci 2013;5:58-62.

38. Nayak AK, Pal D. Tamarind seed polysaccharide-gellan mucoadhesive beads for controlled release of metformin $\mathrm{HCl}$ Carbohydrate Polymer 2014;103:154-63. 